\title{
Specific growth rate and substrate dependent polyhydroxybutyrate production in Saccharomyces cerevisiae
}

\author{
Kanokarn Kocharin and Jens Nielsen ${ }^{*}$
}

\begin{abstract}
Production of the biopolymer polyhydroxybutyrate (PHB) in Saccharomyces cerevisiae starts at the end of exponential phase particularly when the specific growth rate is decreased due to the depletion of glucose in the medium. The specific growth rate and the type of carbon source (fermentable/non-fermentable) have been known to influence the cell physiology and hence affect the fermentability of S. cerevisiae. The production of PHB utilizes cytosolic acetyl-CoA as a precursor and the S. cerevisiae employed in this study is therefore a strain with the enhanced cytosolic acetyl-CoA supply. Growth and PHB production at different specific growth rates were evaluated on glucose, ethanol and a mixture of glucose and ethanol as carbon source. Ethanol as carbon source yielded a higher PHB production compared to glucose since it can be directly used for cytosolic acetyl-CoA production and hence serves as a precursor for PHB production. However, this carbon source results in lower biomass yield and hence it was found that to ensure both biomass formation and PHB production a mixture of glucose and ethanol was optimal, and this resulted in the highest volumetric productivity of PHB, $8.23 \mathrm{mg} / \mathrm{L} \cdot \mathrm{h}^{-1}$, at a dilution rate of $0.1 \mathrm{~h}^{-1}$.
\end{abstract}

Keywords: Polyhydroxybutyrate, Saccharomyces cerevisiae, Specific growth rate

\section{Introduction}

Saccharomyces cerevisiae is a biotechnologically important microorganism. The well-established knowledge and the availability of genome data have led to its versatile use as a cell factory for many industrial products (Ostergaard et al. 2000). Process optimization for production of various industrial products such as biofuels, fine and bulk chemicals in S. cerevisiae has been studied by several research groups (de Jong et al. 2012; Hong and Nielsen 2012; Nevoigt 2008; Ostergaard et al. 2000; Steen et al. 2008). This reveals the physiological adaptability of $S$. cerevisiae to a highly variable environment. According to a respiratory-fermentative metabolism in S. cerevisiae, the type (fermentable/non fermentable) and concentration of carbon source as well as the availability of oxygen are important factors driving the metabolic pattern in the yeast. In order to improve productivity for any

\footnotetext{
* Correspondence: nielsenj@chalmers.se

Department of Chemical and Biological Engineering, Chalmers University of Technology, Kemivägen 10, SE-41296, Göteborg, Sweden
}

products in S. cerevisiae, it is important to know the relationship between growth and product formation.

The bacterial PHB biosynthesis pathway has previously been introduced into the yeast's genome and $S$. cerevisiae has been evaluated as a cell factory for PHB production (Breuer et al. 2002; Dimster-Denk and Rine 1996; Leaf et al. 1996; Marchesini et al. 2003; Zhang et al. 2006). The production of PHB in S. cerevisiae starts at the end of the exponential growth phase specifically when glucose is depleted from the medium (Carlson et al. 2002; Kocharin et al. 2012). From our earlier work, we demonstrated that PHB production can be improved by co-transformation of the plasmid containing the PHB biosynthesis pathway with an acetyl-coenzyme A (acetyl-CoA) boost plasmid designated to improve the availability of cytoplasmic acetylCoA (Kocharin et al. 2012). However, a difference was observed in the productivity when the production was scaled up from shake flasks to bioreactor cultivations. We suspected that the higher specific growth rate obtained in the bioreactor has an effect on PHB production. It is known that the specific growth rate influences the 
physiology of $S$. cerevisiae hence affecting the fermentative capacity, respiratory metabolism and other metabolic activities (Blank and Sauer 2004; Frick and Wittmann 2005; Van Hoek et al. 1998). Therefore, the difference in specific growth rate is hypothesized to be responsible for the lower PHB production in the bioreactor cultivation. In the present study, we employ a chemostat cultivation system to investigate $\mathrm{PHB}$ production at different dilution rates (which correspond to different specific growth rates). Furthermore, we assess PHB production in S. cerevisiae grown on different carbon sources, glucose, ethanol and a mixture of glucose and ethanol.

\section{Materials and methods}

\section{Strains and pre-culture conditions}

$S$. cerevisiae harboring the acetyl-CoA boost plasmid and the PHB plasmid (SCKK006) was used in this study. The acetyl-CoA plasmid contained four genes; alcohol dehydrogenase $(A D H 2)$ and acetaldehyde dehydrogenase (ALD6), acetyl-CoA C-acetyltransferase (ERG10) and acetyl-CoA synthetase (acs ${ }^{\text {L641P }}$ ) from Streptococcus mutans. The details in the acetyl-CoA boost plasmid are described by Chen and co-workers (Chen et al. 2013). The PHB plasmid (pKK01) contained three $\mathrm{PHB}$ genes from Ralstonia eutropha, PhaA ( $\beta$-ketothiolase), PhaB (acetoacetyl-CoA reductase) and PhaC (polyhydroxyalkanoate synthase). All of the heterologous genes were codon optimized for better expression in S. cerevisiae. The details on strain construction have been described previously (Kocharin et al. 2012).

The pre-cultures for bioreactor cultivations were prepared by inoculation of $5 \mathrm{~mL}$ of a defined minimal medium in a $14 \mathrm{~mL}$ culture tube with a single colony and grown at $30^{\circ} \mathrm{C}$ and $180 \mathrm{rpm}$ in an orbital shaking incubator. After $15 \mathrm{~h}$, the culture was transferred into $50 \mathrm{~mL}$ of defined minimal medium in a $500 \mathrm{~mL}$ baffled flask and grown at $30^{\circ} \mathrm{C}$ with $180 \mathrm{rpm}$ in an orbital shaking incubator. The minimal medium for pre-culture cultivations had the same composition as the medium used for bioreactor cultivation.

\section{Chemostat bioreactor cultivation}

PHB production was evaluated in defined minimal media (Verduyn et al. 1992) prepared as follows (per liter): $\left(\mathrm{NH}_{4}\right)_{2} \mathrm{SO}_{4}, 5$ g; $\mathrm{KH}_{2} \mathrm{PO}_{4}, 3$ g; $\mathrm{MgSO}_{4} \cdot 7 \mathrm{H}_{2} \mathrm{O}, 0.5$ g; trace metal solution, $1 \mathrm{~mL}$; and vitamin solution, $1 \mathrm{~mL}$, with an initial $\mathrm{pH}$ of 6.5 . Glucose was autoclaved separately from the minimal medium and later added to the media at the concentration of $20 \mathrm{~g} / \mathrm{L}$. The trace metal solution consisted of the following (per liter): EDTA (sodium salt) $15 \mathrm{~g}$; $\mathrm{ZnSO}_{4} \cdot 7 \mathrm{H}_{2} \mathrm{O}, 0.45 \mathrm{~g} ; \mathrm{MnCl}_{2} \cdot 2 \mathrm{H}_{2} \mathrm{O}, 1 \mathrm{~g} ; \mathrm{CoCl}_{2} \cdot 6 \mathrm{H}_{2} \mathrm{O}$, 0.3 g; $\mathrm{CuSO}_{4} \cdot 5 \mathrm{H}_{2} \mathrm{O}, 0.3$ g; $\mathrm{Na}_{2} \mathrm{MoO}_{4} \cdot 2 \mathrm{H}_{2} \mathrm{O}, 0.4$ g; $\mathrm{CaCl}_{2} \cdot 2 \mathrm{H}_{2} \mathrm{O}, 0.45 \mathrm{~g} ; \mathrm{FeSO}_{4} \cdot 7 \mathrm{H}_{2} \mathrm{O}, 0.3 \mathrm{~g} ; \mathrm{H}_{3} \mathrm{BO}_{3}, 0.1 \mathrm{~g}$ and $\mathrm{KI}, 0.1 \mathrm{~g}$. The $\mathrm{pH}$ of the trace metal solution was adjusted to 4.0 with $2 \mathrm{M} \mathrm{NaOH}$. The vitamin solution contained (per liter): biotin, $0.05 \mathrm{~g}$; $\rho$-amino benzoic acid, 0.2 g; nicotinic acid, $1 \mathrm{~g}$; Ca-pantothenate, $1 \mathrm{~g}$; pyridoxine- $\mathrm{HCl}, 1 \mathrm{~g}$; thiamine- $\mathrm{HCl}, 1 \mathrm{~g}$ and myo-inositol, $25 \mathrm{~g}$. The $\mathrm{pH}$ of the vitamin solution was adjusted to $\mathrm{pH} 6.5$ prior filter sterilization.

The bioreactor was inoculated with an amount of preculture that resulted in a final $\mathrm{OD}_{600}$ of 0.02 . When the glucose and ethanol during batch cultivation was almost completely consumed, the feeding systems for the chemostat operations were started. The aerobic chemostat was performed in 1.0 L stirrer-pro vessels (DasGip, Jülich, Germany) with a working volume of $0.5 \mathrm{~L}$. The temperature was controlled at $30^{\circ} \mathrm{C}$ using a bioBlock integrated heating and cooling thermo well. Agitation was maintained at $600 \mathrm{rpm}$ using an overhead drive stirrer with one Rushton impeller. The air flow rate was kept at 1 vvm. The $\mathrm{pH}$ was maintained constant at 5.0 by the automatic addition of $2 \mathrm{M} \mathrm{KOH}$. Dissolved oxygen was monitored and maintained above 30\% saturation. All the feed media had the same composition and were prepared as described above except for the carbon source. The carbon sources used were $100 \%$ glucose, $100 \%$ ethanol and a mixture of glucose and ethanol at the ratio of 1:2. The carbon sources in the feed medium were prepared based on the $\mathrm{C}$-molar concentration of $20 \mathrm{~g} / \mathrm{L}$ glucose $(0.666 \mathrm{Cmol} / \mathrm{L})$ as in the medium used during batch cultivation. Therefore, feed media with $15.32 \mathrm{~g} / \mathrm{L}$ ethanol, and a mixture of $6.35 \mathrm{~g} / \mathrm{L}$ glucose and $10.21 \mathrm{~g} / \mathrm{L}$ of ethanol were prepared yielding a final carbon concentration of $0.666 \mathrm{Cmol} / \mathrm{L}$. To obtain a dilution rate of $0.05 \mathrm{~h}^{-1}, 0.1 \mathrm{~h}^{-1}, 0.15 \mathrm{~h}^{-1}$ and $0.2 \mathrm{~h}^{-1}$, the inlet medium was fed at $25 \mathrm{ml} / \mathrm{h}, 50 \mathrm{~mL} / \mathrm{h}$, $75 \mathrm{~mL} / \mathrm{h}$ and $100 \mathrm{~mL} / \mathrm{h}$ respectively. Samples were taken when the fermentation reached the steady state, defined by constant values of carbon dioxide transfer rate (CTR), oxygen transfer rate (OTR) and biomass concentration.

\section{Cell mass determination}

Culture samples of $10 \mathrm{~mL}$ volume were centrifuged at $5,000 \mathrm{rpm}$ and $4^{\circ} \mathrm{C}$ for $5 \mathrm{~min}$ and the pellets were washed once with distilled water and centrifuged at $14,000 \mathrm{~g}$ for $1 \mathrm{~min}$. The recovered cell pellet was immediately frozen by immersion in liquid nitrogen followed by lyophilization under vacuum (Christ Alpha 2-4 LSC, Shropshire, UK). The dry cell weight was determined and the pellet kept at $4^{\circ} \mathrm{C}$ for further analysis.

\section{Metabolite analysis}

Metabolites including glucose, ethanol, glycerol, and acetate were quantified in the culture supernatant using an Ultimate 3000 HPLC (Dionex, Sunnyvale, CA, USA) equipped with an Aminex HPX 87H ion exclusion column (300 mm $\times 7.8 \mathrm{~mm}$, Bio-Rad Laboratories, Hercules, CA, USA) which was operated at $45^{\circ} \mathrm{C}$ and a flow rate of $0.6 \mathrm{~mL} / \mathrm{min}$ of $5 \mathrm{mM} \mathrm{H}_{2} \mathrm{SO}_{4}$ using a refractive index 
Table 1 Yields and kinetic parameters obtained from batch cultivations

\begin{tabular}{|c|c|c|c|c|c|c|c|c|}
\hline & $\frac{\mu}{h^{-1}}$ & $\frac{r_{s}}{\mathrm{mmol} / \mathrm{gDW} \cdot \mathrm{h}^{-1}}$ & $\frac{Y_{s x}}{g / C m o l}$ & $\frac{\mathrm{Y}_{\mathrm{sEtOH}}}{\mathrm{Cmol} / \mathrm{Cmol}}$ & $\frac{Y_{\mathrm{sGly}}}{\mathrm{Cmol} / \mathrm{Cmol}}$ & $\frac{\mathrm{Y}_{\mathrm{sPyr}}}{\mathrm{Cmol} / \mathrm{Cmol}}$ & $\frac{Y_{\text {sAce }}}{\mathrm{Cmol} / \mathrm{Cmol}}$ & $\frac{\mathrm{Y}_{\mathrm{sSuc}}}{\mathrm{Cmol} / \mathrm{Cmol}}$ \\
\hline Mean & 0.34 & 3.79 & 1.84 & 0.2293 & 0.0241 & 0.0033 & 0.0064 & 0.0033 \\
\hline SD & 0.01 & 0.52 & 0.26 & 0.01 & 0.00 & 0 & 0 & 0 \\
\hline
\end{tabular}

The values were calculated from at least triplicate fermentations $(n \geq 3)$ and are represented as mean \pm SD.

$\mu=$ specific growth rate; $r_{s}=$ specific substrate uptake rate; $Y_{s x}=$ biomass yield on substrate; $Y_{s E t O H}=$ ethanol yield on substrate; $Y_{s G l y}=$ glycerol yield on substrate; $\mathrm{Y}_{\mathrm{sPyr}}=$ pyruvate yield on substrate; $\mathrm{Y}_{\mathrm{sAce}}=$ acetate yield on substrate; $\mathrm{YsSuc}_{\mathrm{s}}=$ succinate yield on substrate.

detector and UV detector for analysis of sugars and organic acids, respectively.

PHB was analyzed as described previously (Karr et al. 1983; Tyo et al. 2006). 10-20 mg of dried cells were weighed and boiled in $1 \mathrm{~mL}$ of concentrated sulfuric acid for $60 \mathrm{~min}$ and then diluted with $4 \mathrm{~mL}$ of $14 \mathrm{mM} \mathrm{H}_{2} \mathrm{SO}_{4}$. Samples were centrifuged $(15 \mathrm{~min}, 16,000 \times \mathrm{g})$ to remove cell debris, and the supernatant was analyzed using an Ultimate 3000 HPLC (Dionex) equipped with an Aminex HPX-87H ion exclusion column $(300 \times 7.8 \mathrm{~mm}$; Bio- $\mathrm{Rad}$ Laboratories) and UV detector. Commercially available PHB (Sigma-Aldrich, St. Louis, MO), processed in parallel with the samples, was used as a standard. The HPLC was operated at $60^{\circ} \mathrm{C}$ and a flow rate of $0.6 \mathrm{~mL} / \mathrm{min}$ of $5 \mathrm{mM}$ $\mathrm{H}_{2} \mathrm{SO}_{4}$.

\section{Results}

\section{PHB production at different dilution rates}

In this study, we employed a chemostat cultivation technique to investigate $\mathrm{PHB}$ production at different specific growth rates of an engineered $S$. cerevisiae strain, SCKK006, in which genes from the ethanol degradation pathway were overexpressed in order to enhance the supply for acetyl-CoA used as a precursor for PHB production. Besides, we also investigated the production of $\mathrm{PHB}$ when the engineered strain was grown on different carbon sources. In batch cultures, the maximum specific growth rate of SCKK006 on glucose in a defined minimal medium with $20 \mathrm{~g} / \mathrm{L}$ glucose as carbon source was $0.34 \mathrm{~h}^{-1}$. Kinetic parameters and yields during batch cultivation are reported in Table 1 . The ethanol yield and glycerol yield on glucose were $0.2293 \mathrm{Cmol} / \mathrm{Cmol}$ and $0.0241 \mathrm{Cmol} / \mathrm{Cmol}$, respectively. Detectable amounts of pyruvate, succinate and acetate were observed during the batch cultivation. When the ethanol was almost completely depleted from the medium (observed by a drop of the carbon dioxide profile measured from the exhaust gas via a gas analyzer), the chemostat cultivation was started.

The chemostat cultivation was operated at different dilution rates ranging from $0.05 \mathrm{~h}^{-1}$ to $0.2 \mathrm{~h}^{-1}$ with the feed medium containing different carbon sources. The physiological parameters are reported in Table 2. When the feed medium contained glucose as the sole carbon source, ethanol was detected when the dilution rate was higher than $0.1 \mathrm{~h}^{-1}$. This reveals a respiro-fermentative metabolism of S. cerevisiae grown at high dilution rate or high sugar content even in aerobic cultivation with excess oxygen (Hanegraaf et al. 2000). At a dilution rate higher than $0.15 \mathrm{~h}^{-1}$, a very small amount of glycerol $(<10 \mathrm{mg} / \mathrm{L})$ was observed. The highest biomass yield, $0.57 \mathrm{Cmol} / \mathrm{Cmol}$ was found at a dilution rate of $0.1 \mathrm{~h}^{-1}$. At dilution rates higher

Table 2 Yields and kinetic parameters obtained during chemostat cultivations

\begin{tabular}{|c|c|c|c|c|c|c|}
\hline \multirow{2}{*}{$\begin{array}{l}\text { Feeding } \\
\text { component }\end{array}$} & \multirow{2}{*}{$\frac{\text { Dilution rate }}{\mathrm{h}^{-1}}$} & \multirow{2}{*}{$\frac{\mathrm{Y}_{\mathrm{sx}}}{\mathrm{Cmol} / \mathrm{Cmol}}$} & \multirow{2}{*}{$\frac{\mathrm{Y}_{\mathrm{sEtOH}}}{\mathrm{Cmol} / \mathrm{Cmol}}$} & \multirow{2}{*}{$\frac{Y_{\text {sPHB }}}{\mathrm{Cmmol} / \mathrm{Cmol}}$} & \multirow{2}{*}{$\frac{\text { Ethanol accumulation }}{\text { Cmol/L }}$} & \multirow{2}{*}{$\frac{\mathrm{Y}_{\mathrm{xPHB}}}{\mathrm{mg} / \mathrm{gDW}}$} \\
\hline & & & & & & \\
\hline \multirow[t]{4}{*}{ Glucose } & 0.05 & $0.51 \pm 0.01$ & - & $2.51 \pm 0.07$ & 0 & $4.33 \pm 0.19$ \\
\hline & 0.10 & $0.57 \pm 0$ & - & $3.67 \pm 0$ & 0 & $5.59 \pm 0$ \\
\hline & 0.15 & $0.36 \pm 0.02$ & $0.02 \pm 0$ & $2.44 \pm 0$ & - & $5.94 \pm 0.64$ \\
\hline & 0.20 & $0.29 \pm 0$ & $0.1 \pm 0$ & $1.92 \pm 0$ & - & $5.59 \pm 0.23$ \\
\hline \multirow[t]{3}{*}{ Ethanol } & 0.05 & $0.45 \pm 0.01$ & 0 & $8.50 \pm 0.23$ & 0 & $16.55 \pm 0.02$ \\
\hline & 0.10 & $0.37 \pm 0$ & - & $4.94 \pm 0.58$ & $0.0964 \pm 0$ & $13.49 \pm 0$ \\
\hline & 0.15 & $0.12 \pm 0.01$ & - & $0.46 \pm 0.05$ & $0.2364 \pm 0$ & $5.30 \pm 0.31$ \\
\hline \multirow[t]{4}{*}{ Glucose: Ethanol (1:2) } & 0.05 & $0.48 \pm 0.02$ & 0 & $9.97 \pm 0.07$ & 0 & $18.34 \pm 0.53$ \\
\hline & 0.10 & $0.38 \pm 0$ & - & $7.41 \pm 0$ & 0.2012 & $12.41 \pm 0$ \\
\hline & 0.15 & $0.30 \pm 0$ & - & $2.57 \pm 0.1$ & 0.1637 & $7.50 \pm 0.19$ \\
\hline & 0.20 & $0.22 \pm 0$ & - & $1.13 \pm 0$ & 0.2769 & $4.56 \pm 0$ \\
\hline
\end{tabular}

The values were calculated from duplicate fermentations and are represented as mean $\pm \mathrm{SD}$. The formula for biomass used in this calculation is $\mathrm{CH}_{1.8} \mathrm{O}_{0.5} \mathrm{~N}_{0.2}$. $\mathrm{Y}_{\mathrm{sx}}=$ biomass yield on substrate, $\mathrm{Y}_{\mathrm{sEtOH}}=$ ethanol yield on substrate, $\mathrm{Y}_{\mathrm{sPHB}}=\mathrm{PHB}$ yield on substrate, $\mathrm{Y}_{\mathrm{xPHB}}=\mathrm{PHB}$ yield per biomass. 
than $0.1 \mathrm{~h}^{-1}$, the biomass yield tended to decrease. The highest $\mathrm{PHB}$ yield was also observed at a dilution rate of $0.1 \mathrm{~h}^{-1}, 3.67 \mathrm{Cmmol} / \mathrm{Cmol}$ substrate.

When the feed medium contained ethanol as the sole carbon source, the highest biomass yield and PHB yield on substrate, $0.45 \mathrm{Cmol} / \mathrm{Cmol}$ and $8.5 \mathrm{Cmmol} / \mathrm{Cmol}$, was observed when the chemostat was operated at the dilution rate of $0.05 \mathrm{~h}^{-1}$. The biomass yield and the PHB yield tended to decrease when increasing the dilution rate. At dilution rates higher than $0.05 \mathrm{~h}^{-1}$, ethanol accumulated and progressively increased in the medium when the dilution rate was increased. When the chemostat was operated at $0.15 \mathrm{~h}^{-1}$, after 5 residence times, the amount of ethanol accumulated in the medium almost reached the level of ethanol in the feed. When the chemostat was operated at a dilution rate of $0.2 \mathrm{~h}^{-1}$, the biomass decreased and became zero due to washout over 3 resident times.

When glucose or ethanol were used as carbon source, the biomass yield and PHB yield on the mixed-substrate in the feed medium was calculated based on the C-moles of consumed substrate. The maximum biomass yield, $0.48 \pm 0.02 \mathrm{Cmol} / \mathrm{Cmol}$, and the maximum PHB yield, $9.97 \pm 0.07 \mathrm{Cmmol} / \mathrm{Cmol}$, were obtained when the mixed-substrate was fed at $0.05 \mathrm{~h}^{-1}$. Moreover, no accumulation of ethanol was observed when the chemostat was operated at $0.05 \mathrm{~h}^{-1}$ while $0.16-0.28 \mathrm{Cmol} / \mathrm{L}$ of ethanol were observed when the chemostat was operated at dilution rates higher than $0.05 \mathrm{~h}^{-1}$. The amount of accumulated ethanol on the mixed-substrate was similar to the amount of ethanol accumulated in the medium when the chemostat was fed with ethanol alone before the washout occurred The biomass yield on substrate was substantially decreased when the dilution rate was increased on all substrates used in this study.

PHB production in S. cerevisiae grown on different carbon sources

Comparing substrate utilization at the same dilution rate, glucose showed the highest biomass yield on substrate at all dilution rates investigated in this study, followed by the mixed-substrate and ethanol, respectively. The maximum PHB content, $18.34 \mathrm{mg} / \mathrm{gDW}$, was obtained when the mixed substrate was used in the feed at a dilution rate of $0.05 \mathrm{~h}^{-1}$. Comparing either glucose or ethanol as sole carbon source, ethanol alone resulted in a $\sim 3$ times higher PHB yield when the chemostat was operated at $\mathrm{D}=0.05 \mathrm{~h}^{-1}$ although it led to a lower biomass yield on substrate. When the feed medium contained glucose and ethanol as carbon sources, the highest PHB yield was obtained compared to using a single carbon source as a substrate. Comparing the overall volumetric productivities in Figure 1, the mixed-
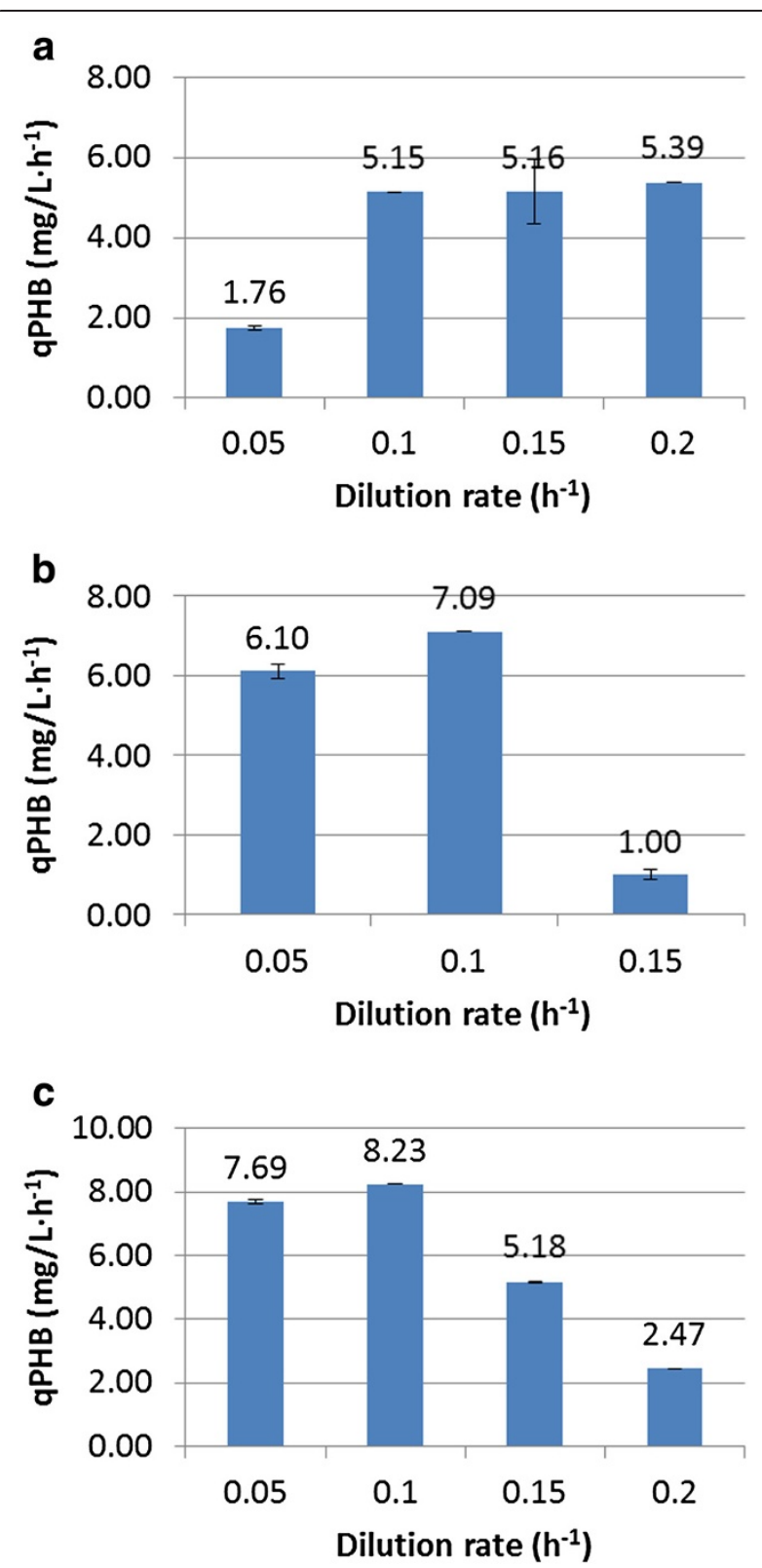

Figure 1 The PHB productivity productivities of recombinant PHB in S. cerevisiae grown on different substrates at different dilution rates from the chemostat cultivation. a) Glucose,

b) Ethanol, c) Mixed-substrate.

substrate at a dilution rate of $0.1 \mathrm{~h}^{-1}$ revealed the highest volumetric productivity of $8.23 \mathrm{mg} / \mathrm{L} \cdot \mathrm{h}^{-1}$. When ethanol was produced during growth on glucose or was accumulated when using ethanol or the mixedsubstrate containing ethanol as a feed medium, the volumetric productivity did not improve. However, when glucose was fed at a dilution rate of $0.2 \mathrm{~h}^{-1}$, a slight increased in the volumetric productivity of $\mathrm{PHB}$ was observed. 


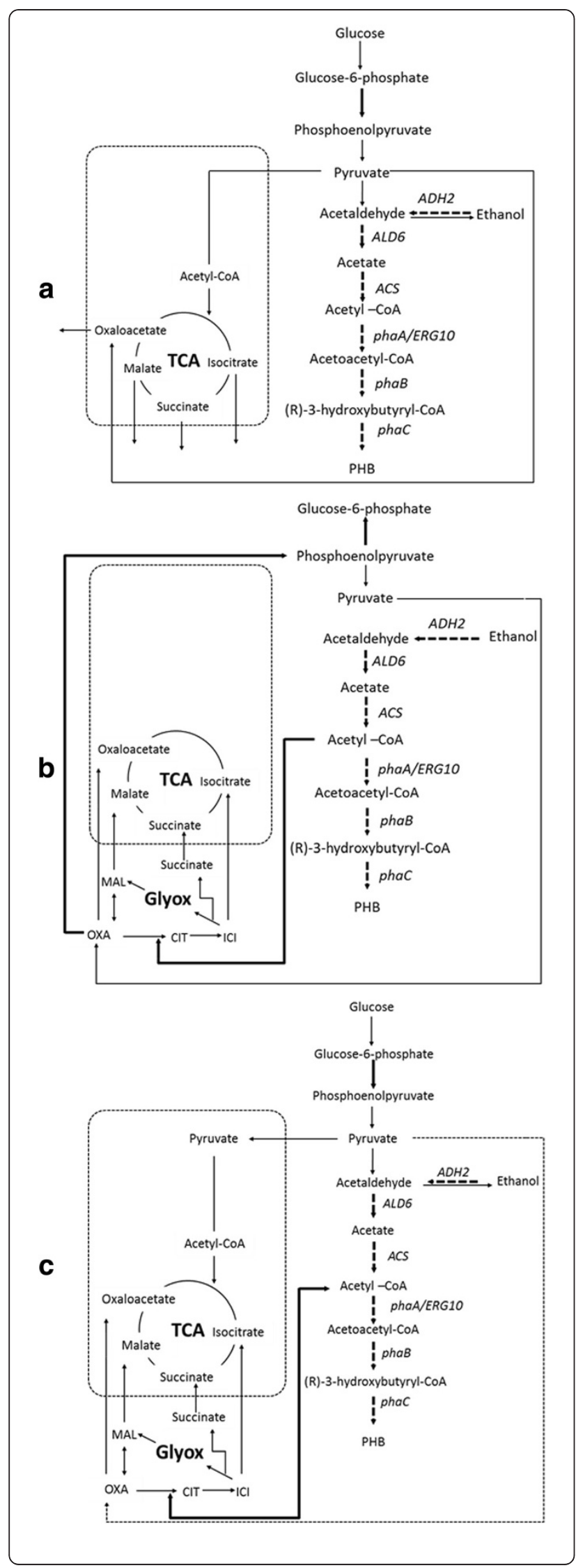

Figure 2 Central carbon metabolism of PHB producing

S. cerevisiae grown on different substrates. a) Glucose, b) Ethanol and $\mathbf{c}$ ) Mixed-substrate of glucose and ethanol. $A D H 2=$ alcohol dehydrogenase; $A L D 6$ = aldehyde dehydrogenase; $A C S=$ acetyl-CoA synthetase $\left(\right.$ acs $\left.^{\mathrm{L} 641 \mathrm{P}}\right)$; ERG10 = acetyl-COA C-acetyltransferase; PhaA (B-ketothiolase); PhaB (acetoacetyl-CoA reductase); PhaC (polyhydroxyalkanoate synthase). $I C l=$ isocitrate; $C I T=$ citrate: OXA = oxaloacetate; $M A L=$ malate; Glyox = glyoxylate.

\section{Discussion}

In S. cerevisiae, high specific growth rate and high sugar concentration trigger the production of ethanol, even during fully aerobic cultivation. In this study, when the chemostat was operated at dilution rates of $0.15 \mathrm{~h}^{-1}$ and $0.2 \mathrm{~h}^{-1}$, ethanol was produced in the medium as an evidence of a respiro-fermentative metabolism of $S$. cerevisiae, which can ferment glucose at a high dilution rate (Duntze et al. 1969; Hanegraaf et al. 2000; Maaheimo et al. 2001). When using glucose as a carbon source in the feed medium, a high specific growth rate (corresponding to a high dilution rate) reduces the flux distribution to the pentose phosphate pathway, which might lower the NADPH concentration (Frick and Wittmann 2005). Since $\mathrm{NADPH}$ is required in the PHB biosynthesis pathway, higher specific growth rates might influence the availability of NADPH and thus substantially lower PHB production. Moreover, production of PHB consumes cytosolic acetyl-CoA which is in this case produced mainly from the overexpression of the ethanol degradation pathway (Figure 2a). Therefore, the PHB yield on glucose was lower than the PHB yield on ethanol. Besides, a small amount of glycerol was produced in order to maintain the redox balance when ethanol was produced from glucose feeding at high dilution rates. In this study, a lower biomass yield on ethanol was observed compared to the biomass yield on glucose at all dilution rates. However, the PHB yield on ethanol was higher compared with using only glucose in the feed medium. This might be due to the fact that ethanol in the feed replaces pyruvate as the direct source for cytosolic acetyl-CoA production and hence results in a higher $\mathrm{Y}_{\mathrm{sPHB}}$ compared to with glucose as carbon source (Figure 2b). When S. cerevisiae is grown on ethanol, the synthesis of biomass and the TCA intermediates requires activity of the glyoxylate and gluconeogenesis pathways (de Jong-Gubbels et al. 1995; Maaheimo et al. 2001) and this explains the lower biomass yield compared to glucose. When $S$. cerevisiae is grown on the glucose and ethanol mixture, glucose is used as carbon and energy source for growth whereas ethanol can serve as the main source for cytosolic acetyl-CoA production and hence the carbon source for PHB production (de Jong-Gubbels et al. 1995) (Figure 2c). Therefore, the mixed-substrate used in this study resulted in higher 
biomass and PHB yields on substrate compared to the use of a single substrate in the feed medium. However, when the mixed-substrate was fed at a dilution rate higher than $0.05 \mathrm{~h}^{-1}$, ethanol started to accumulate ranging from $0.16 \mathrm{Cmol} / \mathrm{L}$ to $0.2 \mathrm{Cmol} / \mathrm{L}$. The accumulated ethanol at higher dilution rates affected the ratio of glucose and ethanol in the bioreactor, thus influencing the overall regulation of the central carbon metabolism (de Jong-Gubbels et al. 1995) and eventually resulting in washout of the cells from the continuous bioreactor. In conclusion, ethanol is a better carbon source for PHB production in yeast compared to glucose since it can be directly used for acetyl-CoA production and hence serve as a precursor for PHB production. In terms of productivity, to compromise between growth of $S$. cerevisiae and PHB production, feeding of a mixed-substrate at the appropriate ratio between glucose and ethanol, where no ethanol accumulate in the medium, i.e. the chemostat operated at a dilution rate of $0.1 \mathrm{~h}^{-1}$ results in maximum $\mathrm{PHB}$ production.

\section{Competing interests}

The authors declare that they have no competing interest.

\section{Authors' contributions}

KK and JN participated in the design of the experiment. KK performed all the experiments, analyzed the data and wrote the manuscript. JN edited the manuscript. All authors read and approved the final manuscript.

\section{Acknowledgements}

We thank Chalmers Foundation and the Knut and Alice Wallenberg Foundation for funding part of this work. We also acknowledge the Thailand Science and Technology Ministry for providing a stipend to KK.

Received: 22 January 2013 Accepted: 14 March 2013

Published: 21 March 2013

\section{References}

Blank LM, Sauer U (2004) TCA cycle activity in Saccharomyces cerevisiae is a function of the environmentally determined specific growth and glucose uptake rates. Microbiol 150(Pt 4):1085-1093

Breuer U, Terentiev Y, Kunze G, Babel W (2002) Yeasts as producers of polyhydroxyalkanoates: genetic engineering of Saccharomyces cerevisiae. Macromol Biosci 2(8):380-386

Carlson R, Fell D, Srienc F (2002) Metabolic pathway analysis of a recombinant yeast for rational strain development. Biotechnol Bioeng 79(2):121-134

Chen Y, Daviet L, Schalk M, Siewers V, Nielsen J (2013) Establishing a platform cell factory through engineering of yeast acetyl-CoA metabolism. Metab Eng 15:48-54

de Jong B, Siewers V, Nielsen J (2012) Systems biology of yeast: enabling technology for development of cell factories for production of advanced biofuels. Curr Opin Biotechnol 23(4):624-630

de Jong-Gubbels P, Vanrolleghem P, Heijnen S, van Dijken JP, Pronk JT (1995) Regulation of carbon metabolism in chemostat cultures of Saccharomyces cerevisiae grown on mixtures of glucose and ethanol. Yeast 11(5):407-418

Dimster-Denk D, Rine J (1996) Transcriptional regulation of a sterol-biosynthetic enzyme by sterol levels in Saccharomyces cerevisiae. Mol Cell Biol 16(8):3981-3989

Duntze W, Neumann D, Gancedo JM, Atzpodien W. Holzer H (1969) Studies on the regulation and localization of the glyoxylate cycle enzymes in Saccharomyces cerevisiae. Eur J Biochem/FEBS 10(1):83-89

Frick O, Wittmann C (2005) Characterization of the metabolic shift between oxidative and fermentative growth in Saccharomyces cerevisiae by comparative ${ }^{13} \mathrm{C}$ flux analysis. Microb Cell Fact 4(1):30
Hanegraaf PP, Stouthamer AH, Kooijman SA (2000) A mathematical model for yeast respiro-fermentative physiology. Yeast 16(5):423-437

Hong KK, Nielsen J (2012) Metabolic engineering of Saccharomyces cerevisiae: a key cell factory platform for future biorefineries. Cell Mol Life Sci 69(16):2671-2690

Karr DB, Waters JK, Emerich DW (1983) Analysis of poly- $\beta$-hydroxybutyrate in Rhizobium japonicum bacteroids by ion-exclusion high-pressure liquid chromatography and UV detection. Appl Environ Microbiol 46(6):1339-1344

Kocharin K, Chen Y, Siewers V, Nielsen J (2012) Engineering of acetyl-CoA metabolism for the improved production of polyhydroxybutyrate in Saccharomyces cerevisiae. AMB Express 2(1):52

Leaf TA, Peterson MS, Stoup SK, Somers D, Srienc F (1996) Saccharomyces cerevisiae expressing bacterial polyhydroxybutyrate synthase produces poly-3hydroxybutyrate. Microbiol 142(Pt 5):1169-1180

Maaheimo H, Fiaux J, Cakar ZP, Bailey JE, Sauer U, Szyperski T (2001) Central carbon metabolism of Saccharomyces cerevisiae explored by biosynthetic fractional ${ }^{13} \mathrm{C}$ labeling of common amino acids. Eur J Biochem/FEBS 268 (8):2464-2479

Marchesini S, Erard N, Glumoff T, Hiltunen JK, Poirier Y (2003) Modification of the monomer composition of polyhydroxyalkanoate synthesized in Saccharomyces cerevisiae expressing variants of the $\beta$-oxidation-associated multifunctional enzyme. Appl Environ Microbiol 69(11):6495-6499

Nevoigt E (2008) Progress in metabolic engineering of Saccharomyces cerevisiae. Microbiol Mol Biol Rev 72(3):379-412

Ostergaard S, Olsson L, Nielsen J (2000) Metabolic Engineering of Saccharomyces cerevisiae. Microbiol Mol Biol Rev 64(1):34-50

Steen E, Chan R, Prasad N, Myers S, Petzold C, Redding A, Ouellet M, Keasling J (2008) Metabolic engineering of Saccharomyces cerevisiae for the production of n-butanol. Microb Cell Fact 7(1):36

Tyo KE, Zhou H, Stephanopoulos GN (2006) High-throughput screen for poly-3 -hydroxybutyrate in Escherichia coli and Synechocystis sp. strain PCC6803. Appl Environ Microbiol 72(5):3412-3417

Van Hoek P, Van Dijken JP, Pronk JT (1998) Effect of specific growth rate on fermentative capacity of baker's yeast. Appl Environ Microbiol 64(11):4226-4233

Verduyn C, Postma E, Scheffers WA, Vandijken JP (1992) Effect of benzoic-acid on metabolic fluxes in yeasts - a continuous-culture study on the regulation of respiration and alcoholic fermentation. Yeast 8(7):501-517

Zhang B, Carlson R, Srienc F (2006) Engineering the monomer composition of polyhydroxyalkanoates synthesized in Saccharomyces cerevisiae. Appl Environ Microbiol 72(1):536-543

doi:10.1186/2191-0855-3-18

Cite this article as: Kocharin and Nielsen: Specific growth rate and substrate dependent polyhydroxybutyrate production in Saccharomyces cerevisiae. AMB Express 2013 3:18.

\section{Submit your manuscript to a SpringerOpen ${ }^{\circ}$ journal and benefit from:}

- Convenient online submission

Rigorous peer review

- Immediate publication on acceptance

- Open access: articles freely available online

- High visibility within the field

- Retaining the copyright to your article

Submit your next manuscript at $>$ springeropen.com 